\title{
Insidensi Tuberkulosis Paru pada Pasien Diabetes Melitus Tipe 2 di Ruang Rawat Inap Penyakit Dalam RSUP Dr. M. Djamil Padang
}

\author{
Dina Fitri Fauziah ${ }^{1}$, Masrul Basyar ${ }^{2}$, Asman Manaf $^{3}$
}

\begin{abstract}
Abstrak
Diabetes melitus (DM) merupakan suatu penyakit metabolik dengan karakteristik hiperglikemia akibat kelainan sekresi dan/atau gangguan kerja insulin. Sekitar $80 \%$ dari seluruh kasus DM merupakan DM tipe 2. Salah satu komplikasi DM adalah tuberkulosis (TB) paru. Tujuan penelitian ini adalah mengevaluasi insidensi TB paru pada pasien DM tipe 2 di Ruang Rawat Inap Penyakit Dalam RSUP Dr. M. Djamil Padang. Instrumen penelitian yang digunakan adalah data sekunder dari Instalasi Rekam Medis RSUP Dr. M. Djamil Padang berupa data pasien DM tipe 2 dan rekam medik pasien DM tipe 2 dengan TB paru yang dirawat di Ruang Rawat Inap Penyakit Dalam RSUP Dr. M. Djamil Padang sejak 1 Januari 2011 - 31 Desember 2011. Hasil penelitian ini menunjukkan bahwa terdapat 29 kasus TB paru dari 748 orang pasien DM tipe 2 (3,88\%). Kasus DM tipe 2 dengan TB paru terbanyak ditemukan pada kelompok jenis kelamin laki-laki (58,62\%), usia < 60 tahun (72,41\%; mean: 54,66 $\pm 12,77$ tahun), dan normoweight $(51,72 \%)$. Sebagian besar pasien menunjukkan hasil pemeriksaan BTA sputum negatif $(65,52 \%)$. Insidensi pada penelitian ini sedikit lebih rendah daripada hasil penelitian sebelumnya.
\end{abstract}

Kata kunci: insidensi, tuberkulosis paru, diabetes melitus tipe 2

\begin{abstract}
Diabetes mellitus (DM) is a group of metabolic disorders characterized by hyperglycemia resulting from defects in insulin secretion, insulin action or both. Type 2 DM makes up about $80 \%$ of all cases of DM. One of the DM's complications is pulmonary tuberculosis (TB). The objective of this study was to evaluate the incidence of pulmonary TB among type 2 DM patients in Internal Medicine Ward RSUP Dr. M. Djamil Padang. The instruments used in this research were the secondary data derived from the Medical Record Departement RSUP Dr. M. Djamil Padang in the form of type 2 DM patients' data and medical records of type 2 DM patients with pulmonary TB who were treated in Internal Medicine Ward RSUP Dr. M. Djamil Padang since January 1st 2011 - December 31st 2011. The results of this research showed that there were 29 cases of pulmonary TB among 748 type 2 DM patients (3,88\%). Most of type 2 DM with pulmonary TB cases were found in males $(58,62 \%),<60$ years old $(72,41 \%$; mean: $54,66 \pm 12,77$ years old), and normoweight group $(51,72 \%)$. Most of these patients showed negative results on the sputum AFB examination $(65,52 \%)$. The incidence in this research is lower than the previous studies.
\end{abstract}

Keywords: incidence, pulmonary tuberculosis, type 2 diabetes mellitus

Affiliasi penulis: 1. Pendidikan Dokter FK UNAND (Fakultas Kedokteran Universitas Andalas Padang), 2. Bagian Pumonologi dan IImu Kedokteran Respirasi FK UNAND/RSUP Dr.M. Djamil Padang, 3. Bagian IImu Penyakit Dalam FK UNAND/RSUP Dr.M. Djamil Padang . Korespondensi: Dina Fitri Fauziah, Email: dinafitrifauziah@gmail.com, Telp: 081266407299

\begin{abstract}
PENDAHULUAN
Diabetes melitus (DM) merupakan suatu kelompok penyakit metabolik dengan karakteristik hiperglikemia akibat kelainan sekresi insulin, kerja insulin, ataupun kedua-duanya.Sekitar $80 \%$ dari seluruh kasus DM merupakan DM tipe 2. ${ }^{1}$ Diabetes
\end{abstract}


melitus merupakan ancaman global dan serius dari kelompok penyakit tidak menular. International Diabetes Federation (IDF) menyatakan bahwa terdapat 366 juta $(8,3 \%)$ orang penderita DM di seluruh dunia pada tahun $2011 .^{2}$ Indonesia menempati peringkat keempat negara dengan prevalensi DM terbanyak di dunia setelah Amerika Serikat, China dan India pada tahun 2011. ${ }^{3}$ Hasil penelitian Badan Penelitian dan Pengembangan Departemen Kesehatan Republik Indonesia (Litbang Depkes RI) di seluruh provinsi di Indonesia yang dipublikasikan pada Desember 2008 menunjukkan bahwa prevalensi nasional Toleransi Glukosa Terganggu (TGT) pada penduduk usia > 15 tahun adalah sebesar 10,25\% dan prevalensi nasional DM adalah sebesar $5,7 \%{ }^{4}$

Diabetes melitus dapat menimbulkan berbagai macam komplikasi. Salah satunya adalah tuberkulosis paru. ${ }^{5,6} \mathrm{Hal}$ ini terlihat dari peningkatan kasus TB pada pasien DM, terutama pada daerah epidemi DM dan TB seperti: Cina, India dan Indonesia. Tiga negara ini mengalami peningkatan prevalensi DM tercepat dan memiliki beban TB tertinggi di dunia. ${ }^{7}$ Prevalensi TB paru pada DM meningkat 20 kali lipat dibandingkan dengan prevalensi TB paru pada non-DM. Suatu penelitian melaporkan bahwa prevalensi pasien DM yang mengalami TB di Indonesia adalah sebesar $12,8 \%-42 \% .^{5}$

Prevalensi TB paru pada DM cenderung meningkat seiring dengan bertambahnya usia. $^{7}$ Nasution melaporkan 37,2\% pasien DM dengan TB paru di RSUP H. Adam Malik Medan termasuk dalam kelompok usia 51 - 60 tahun. $^{8}$ Sebagian besar $(63,8 \%)$ dari pasien tersebut adalah laki-laki. Pasien DM laki-laki mempunyai risiko 2 kali lebih tinggi mendapatkan TB paru dibandingkan dengan pasien DM wanita. ${ }^{5}$

Salah satu faktor risiko DM adalah berat badan yang berlebih, namun pasien DM cenderung mengalami penurunan berat badan seiring dengan perjalanan penyakit. Tuberkulosis paru merupakan penyakit kronis yang juga memberikan gejala penurunan berat badan. ${ }^{9}$ Suatu penelitian menyatakan bahwa hanya $15 \%$ pasien DM dengan TB paru yang termasuk kelompok obesitas berdasarkan indeks massa tubuhnya. Sebagian besar $(71 \%)$ dari pasien tersebut termasuk kelompok non-obesitas dan 14\% lainnya termasuk dalam kelompok kurus. ${ }^{5}$

Perjalanan penyakit TB paru pada DM cenderung berat dan kronis. ${ }^{5,7}$ Sebanyak 65,9\% pasien DM dengan TB paru di RSUP H. Adam Malik Medan memiliki hasil positif pada pemeriksaan basil tahan asam (BTA) sputumnya. ${ }^{8}$ Penelitian lain melaporkan hanya terdapat 30\% pasien DM dengan TB paru yang hasil BTA sputumnya positif. ${ }^{10}$

Angka kejadian DM di Indonesia semakin meningkat, demikian juga angka kejadian TB paru di Indonesia juga masih sangat tinggi. Penurunan imunitas pada pasien DM dapat meningkatkan risiko infeksi TB paru. Berdasarkan hal tersebut, maka perlu diteliti insidensi TB Paru pada pasien DM tipe 2 di Ruang Rawat Inap Penyakit Dalam RSUP DR. M. Djamil Padang.

Tujuan penelitian ini adalah untuk mengetahui insidensi TB paru pada pasien DM tipe 2 di Ruang Rawat Inap Penyakit Dalam RSUP DR. M. Djamil Padang dan distribusi frekuensinya berdasarkan jenis kelamin, usia, IMT dan hasil BTA sputum.

\section{METODE}

Penelitian dilakukan di Instalasi Rekam Medik RSUP DR. M. Djamil Padang sejak Desember 2011 Januari 2013. Populasi penelitian ini adalah seluruh data rekam medis pasien yang didiagnosis sebagai penderita DM tipe 2 yang dirawat di Ruang Rawat Inap Penyakit Dalam RSUP DR. M. Djamil Padang sejak 1 Januari 2011 - 31 Desember 2011. Sampel penelitian ini adalah seluruh populasi dengan kriteria eksklusi berupa pasien DM tipe 2 dengan TB paru yang tidak lengkap data nama, jenis kelamin, usia, berat badan, tinggi badan dan hasil pemeriksaan BTA sputumnya.

\section{HASIL}

Tabel 1. Insidensi tuberkulosis paru pada pasien diabetes melitus tipe 2

\begin{tabular}{ccc}
\hline \multirow{2}{*}{ TB Paru } & \multicolumn{2}{c}{ Diabetes Melitus Tipe 2 } \\
\cline { 2 - 3 } & $\mathbf{n}$ & $\mathbf{( \% )}$ \\
\hline$(+)$ & 29 & 3,88 \\
\hline$(-)$ & 719 & 96,12 \\
\hline Total & 748 & 100 \\
\hline
\end{tabular}


Tabel 1 memperlihatkan gambaran insidensi TB paru pada pasien DM tipe 2. Berdasarkan data yang diperoleh, terdapat 748 orang pasien DM tipe 2 yang dirawat di Ruang Rawat Inap Penyakit Dalam RSUP Dr. M. Djamil Padang selama tahun 2011. Dari jumlah tersebut, ditemukan 29 orang pasien DM tipe 2 yang juga didiagnosis menderita TB paru. Insidensi TB paru pada pasien DM tipe 2 adalah 3,88\%.

Tabel 2. Distribusi frekuensi pasien diabetes melitus tipe 2 dengan tuberkulosis paru menurut jenis kelamin

\begin{tabular}{llc}
\hline \multicolumn{1}{c}{ Jenis Kelamin } & $\mathbf{n}$ & $(\%)$ \\
\hline Laki-laki & 7 & 58,62 \\
\hline Perempuan & 2 & 41,38 \\
\hline Total & 9 & 100 \\
\hline
\end{tabular}

Tabel 2 terlihat bahwa sebagian besar pasien DM tipe 2 dengan TB paru berjenis kelamin laki-laki, yaitu 17 orang $(58,62 \%)$, sedangkan pasien DM tipe 2 dengan TB paru yang berjenis kelamin perempuan berjumlah 12 orang $(41,38 \%)$.

Tabel 3. Distribusi frekuensi pasien diabetes melitus tipe 2 dengan tuberkulosis paru menurut usia

\begin{tabular}{ccc}
\hline Usia (tahun) & $\mathbf{n}$ & (\%) \\
\hline$<60$ & 1 & 72,41 \\
\hline$\geq 60$ & 8 & 27,59 \\
\hline Total & 9 & 100
\end{tabular}

Data dari Tabel 3 memperlihatkan bahwa insidensi DM tipe 2 dengan TB paru terbanyak berasal dari kelompok usia < 60 tahun, yaitu 21 orang $(72,41 \%)$. Berdasarkan perhitungan, didapatkan ratarata usia pasien adalah $54,66 \pm 12,77$ tahun.

Tabel 4. Distribusi frekuensi pasien diabetes melitus tipe 2 dengan tuberkulosis paru menurut Indeks Massa Tubuh (IMT)

\begin{tabular}{ccc}
\hline IMT & F & (\%) \\
\hline Underweight & 10 & 34,48 \\
\hline Normoweight & 5 & 51,72 \\
\hline Overweight & 4 & 13,79 \\
\hline Total & 29 & 100
\end{tabular}

Berdasarkan Tabel 4, dapat dilihat bahwa pasien DM tipe 2 dengan TB paru terbanyak berasal dari kelompok normoweight, yaitu 15 orang (51,72\%). Sedangkan pasien dari kelompok overweight hanya berjumlah 4 orang (13,79\%).

Tabel 5. Distribusi frekuensi diabetes melitus tipe 2 dengan tuberkulosis paru menurut hasil pemeriksaan Basil Tahan Asam (BTA) sputum

\begin{tabular}{ccc}
\hline $\begin{array}{c}\text { Hasil Pemeriksaan BTA } \\
\text { Sputum }\end{array}$ & $\mathbf{n}$ & $\mathbf{( \% )}$ \\
\hline BTA (+) & 10 & 34,48 \\
\hline BTA (-) & 19 & 65,52 \\
\hline Total & 29 & 100 \\
\hline
\end{tabular}

Pada Tabel 5, dapat dilihat bahwa sebagian besar pasien DM tipe 2 dengan TB paru memiliki hasil pemeriksaan BTA sputum negatif, yaitu sebanyak 19 orang (65,52\%). Pasien DM tipe 2 dengan TB paru BTA positif berjumlah sebanyak 10 orang $(34,48 \%)$.

\section{PEMBAHASAN}

Penelitian insidensi TB paru pada pasien DM tipe 2 ini dilakukan terhadap 748 orang pasien DM tipe 2 yang dirawat di Ruang Rawat Inap Penyakit Dalam RSUP Dr. M. Djamil Padang selama tahun 2011. Dari 748 orang pasien DM tipe 2 tersebut, 29 orang di antaranya juga didiagnosis dengan TB paru, sehingga menghasilkan angka insidensi TB paru pada pasien DM tipe 2 sebesar 3,88\%. Angka ini sedikit lebih rendah dibandingkan dengan hasil penelitian sebelumnya yang menemukan adanya $4,5 \%$ pasien DM tipe 2 dengan TB paru di Poliklinik RSUP Dr. M. Djamil Padang selama Juni 2010 sampai Juni $2011{ }^{7}$ Angka ini juga lebih rendah dibandingkan dengan hasil penelitian sebelumnya yang menunjukkan bahwa prevalensi TB paru pada pasien DM tipe 2 di Indonesia berkisar antara $12,8 \%-42 \%{ }^{5}$ Rendahnya angka insidensi ini juga dapat disebabkan oleh cakupan sampel dalam penelitian ini yang hanya meliputi pasien di Ruang Rawat Inap Penyakit Dalam RSUP Dr. M. Djamil Padang pada tahun 2011 saja. Angka kejadian yang lebih besar kemungkinan akan 
dapat diperoleh jika dilakukan penelitian pada cakupan sampel yang lebih luas.

Pada Tabel 2 ditemukan lebih banyak pasien DM tipe 2 dengan TB paru yang berjenis kelamin lakilaki $(58,62 \%)$ dibandingkan dengan perempuan $(41,38 \%)$. Hal ini sesuai dengan hasil beberapa penelitian lainnya yang menyatakan bahwa kasus TB paru pada pasien DM tipe 2 lebih banyak terjadi pada pasien yang berjenis kelamin laki-laki dibandingkan dengan perempuan. ${ }^{5,6}$ Hasil ini juga hampir sama dengan hasil penelitian di RSUP $H$. Adam Malik Medan pada tahun 2007 yang menunjukkan bahwa $63,8 \%$ pasien DM tipe 2 dengan TB paru berjenis kelamin laki-laki. ${ }^{8}$

Menurut beberapa penelitian, terlepas dari ada atau tidaknya diabetes melitus, laki-laki memang lebih rentan terkena infeksi $M$. tuberculosis. Hal ini dapat berkaitan dengan kebiasaan merokok yang lebih besar pada laki-laki, yang menyebabkan gangguan pada sistem imunitas saluran pernafasan sehingga menjadi lebih rentan untuk terinfeksi. ${ }^{11}$ Gangguan pada sistem imunitas saluran pernafasan tersebut dapat berupa kerusakan bersihan mukosiliar akibat racun pada asap rokok yang terhirup. Asap rokok tersebut juga dapat merusak sel-sel fagosit di saluran pernafasan dan menurunkan respon terhadap antigen, sehingga meningkatkan kerentanan tuberkulosis paru. ${ }^{12}$

WHO (2012) juga menyatakan bahwa menurut beberapa penelitian, insidensi TB paru pada perempuan lebih rendah dibandingkan pada laki-laki karena lebih sedikitnya perempuan dengan TB paru yang berobat ke fasilitas pelayanan kesehatan. Hal ini terjadi karena perempuan cenderung lebih sulit mengakses fasilitas pelayanan kesehatan. Stigma negatif masyarakat tentang TB paru lebih mempengaruhi aspek psikososial perempuan dibandingkan laki-laki, sehingga perempuan cenderung memilih untuk tidak berobat ke fasilitas pelayanan kesehatan. ${ }^{11}$

Data Tabel 3 ditemukan kasus DM tipe 2 dengan TB paru paling banyak terjadi pada usia kurang dari 60 tahun (72,41\%). Secara keseluruhan didapatkan rata-rata usia pasien sebesar 54,66 \pm 12,77 tahun. Nilai rata-rata usia pasien sebesar 54,66 $\pm 12,77$ tahun (mendekati usia 60 tahun) tersebut menandakan adanya kecenderungan peningkatan insidensi TB paru pada DM seiring dengan meningkatnya usia. Hal ini sesuai dengan hasil penelitian sebelumnya yang menyatakan bahwa risiko terjadinya tuberkulosis pada pasien DM lebih besar pada usia yang lebih tua. ${ }^{5}$ Hasil ini hampir sama dengan hasil penelitian Tadar et al yang menyebutkan bahwa usia rata-rata pasien DM dengan TB paru adalah 53,55 $\pm 12,66$ tahun. $^{13}$ Beberapa penelitian lainnya juga menyatakan bahwa kasus DM dengan TB paru paling banyak ditemukan pada pasien dengan rentang usia $40-50$ tahunan. $^{14}$

Pasien usia lanjut rentan lebih rentan untuk terkena infeksi M. tuberculosis. ${ }^{15} \mathrm{Hal}$ ini disebabkan oleh ada perubahan biologis yang terjadi pada tubuh pasien, terutama pada jaringan paru, terkait dengan penuaan. Perubahan tersebut dapat merusak sistem barier dan mekanisme klirens mikrobial pada sistem pernafasan. Pasien usia lanjut juga lebih rentan mengalami malnutrisi. Hal tersebut berkontribusi dalam menurunnya respon imun seluler terhadap $M$. tuberculosis. Hiperglikemia yang semakin tidak terkontrol akibat fungsi sel beta yang lebih terganggu dan faktor kontrol yang tidak teratur pada usia lanjut dapat semakin mengganggu sistem imunitas tubuh sehingga juga menjadi penyebab tingginya prevalensi TB paru pada pasien DM usia lanjut.,

Tabel 4 dapat dilihat bahwa pasien DM tipe 2 dengan TB paru terbanyak berasal dari kelompok normoweight (51,72\%). Angka ini disusul oleh kelompok underweight $(34,48 \%)$. Hanya sebagian kecil pasien berasal dari kelompok overweight $(13,79 \%)$. Hasil ini sesuai dengan penelitian sebelumnya yang menyatakan bahwa sebagian besar (71\%) pasien DM dengan TB paru merupakan normoweight. ${ }^{5,16}$

Sedikitnya pasien dari kelompok overweight dapat disebabkan karena terjadinya penurunan berat badan sebagai salah satu gejala klinis penyakit yang sedang dideritanya. Salah satu faktor risiko DM adalah berat badan yang berlebih (overweight), namun pasien DM cenderung mengalami penurunan berat badan seiring dengan perjalanan penyakit. TB paru merupakan penyakit kronis yang juga memberikan gejala penurunan berat badan. ${ }^{9}$ Penurunan berat 
badan tersebut dapat menjadikan status IMT pasien berubah dari kelompok overweight menjadi kelompok normoweight atau underweight.

Tabel 5 memperlihatkan bahwa sebagian besar pasien DM tipe 2 dengan TB paru memiliki hasil pemeriksaan BTA sputum negatif, yaitu 19 orang $(65,52 \%)$. Hasil ini sesuai dengan hasil penelitian sebelumnya yang menyatakan bahwa $70 \%$ pasien DM dengan TB paru memiliki hasil pemeriksaan BTA sputum negatif, dan hanya $30 \%$ yang hasil pemeriksaan BTA sputumnya positif. ${ }^{10}$ Penelitian lain melaporkan bahwa dari 100 orang pasien DM di India, 27\% didiagnosis TB paru dengan BTA negatif dan hanya $6 \%$ yang didiagnosis TB paru dengan BTA positif. ${ }^{16}$ Ada penelitian lain yang melaporkan hasil yang berbeda, yaitu 65,9\% pasien DM dengan TB paru di RSUP $\mathrm{H}$. Adam Malik Medan memiliki hasil positif pada pemeriksaan bakteriologi BTA sputumnya. $^{8}$

Sedikitnya pasien yang hasil pemeriksaan BTA sputumnya positif pada penelitian ini dapat disebabkan karena sulitnya mendapatkan spesimen sputum pasien akibat pasien yang tidak dapat mengeluarkan dahak secara spontan. ${ }^{17} \mathrm{Hal}$ ini dapat disebabkan karena tingginya keterlibatan lapangan paru bawah pada pasien TB paru dengan DM sehingga proses ekspektorasi menjadi kurang efisien. ${ }^{5,8,18}$ Penelitian Tadar et al menemukan bahwa 37,2\% pasien TB paru dengan DM memiliki gambaran radiologis atipikal yang melibatkan lobus tengah dan bawah paru. ${ }^{13}$ Menurut Berger dan Granada, keterlibatan lapangan paru bawah tersebut sering disebabkan oleh perforasi transbronkial nodus limfe hilus paru sehingga infeksi menyebar ke jaringan paru di sekitarnya. ${ }^{18}$ Penelitian lainnya menyebutkan bahwa hal ini lebih disebabkan oleh peningkatan tekanan oksigen alveolar di lobus bawah paru akibat perubahan stuktur histologis dan fungsional jaringan paru yang sering terjadi pada pasien DM. ${ }^{19}$

\section{KESIMPULAN}

Insidensi TB paru pada DM tipe 2 di Ruang Rawat Inap Penyakit Dalam RSUP Dr. M. Djamil Padang adalah sebesar 3,88\%.Frekuensi DM tipe 2 dengan TB paru ditemukan lebih banyak pada kelompok jenis kelamin laki-laki, usia < 60 tahun dengan rata-rata usia 54,66 $\pm 12,77$ tahun, dan status IMT normoweight. Pasien DM tipe 2 dengan TB paru paling banyak memiliki hasil BTA sputum negatif.

\section{DAFTAR PUSTAKA}

1. Direktorat Jenderal Pengendalian Penyakit dan Penyehatan Lingkungan Kementrian Kesehatan Republik Indonesia. Situasi TB di Indonesia dalam pencapaian MDGs. 2011.

2. Whiting DR, Guariguata L, Weil C, Shaw J. IDF diabetes atlas: global estimates of the prevalence of diabetes for 2011 and 2030. Diabetes Research and Clinical Practice. Elsevier Ireland Ltd. 2011; Dec;94(3):311-21.

3. Pusat Data dan Informasi Perhimpunan Rumah Sakit Seluruh Indonesia.RI. Rangking keempat jumlah penderita diabetes terbanyak dunia.2011.

4. Suyono S. Kecenderungan peningkatan jumlah penyandang diabetes. penatalaksanaan diabetes melitus terpadu. Edisi ke-2. Jakarta: Balai Penerbitan Fakultas Kedokteran Universitas Indonesia; 2011. hlm.6-22.

5. Sanusi H. Diabetes melitus dan tuberkulosis paru. Jurnal Medika Nusantara. 2006;25(1).

6. Nazulis RA. Drug related problems pada pasien diabetes melitus tipe 2 dengan tuberkulosis paru di bangsal penyakit dalam dan poliklinik RSUP. Dr. M. Djamil Padang. Padang: Fakultas Kedokteran Universitas Andalas. 2011.

7. Cahyadi A, Venty. Tuberkulosis paru pada pasien diabetes mellitus. Majalah Kedokteran Indonesia. 2011;61(4):173-8.

8. Nasution EJS. Profil penderita tuberkulosis paru dengan diabetes melitus dihubungkan dengan kadar gula darah puasa (tesis). Medan: Fakultas Kedokteran Universitas Sumatera Utara. 2007.

9. Amin Z, Bahar A. Tuberkulosis paru. Buku Ajar IImu Penyakit Dalam.Jilid II. Edisi ke-4. Jakarta: Pusat Penerbitan Departemen IImu Penyakit Dalam Fakultas Kedokteran Universitas Indonesia; 2006. hlm.998-1000.

10. Kirani KRLS, Kumari VS, Kumari RL. Co-existence of pulmonary tuberculosis and diabetes mellitus: some observations. Ind J Tub. 1998;45(47). 
11.World Health Organization. Gender and tuberculosis. .2012.

12. Wang J, Shen $\mathrm{H}$. Review of cigarette smocking and tuberculosis in China: intervention is needed for smocking cessation among tuberculosis patients. BMC Public Health. 2009;9:292.

13. Tadar D, Senol G, Alptekin S, Karakurum C, Aydin $\mathrm{M}$, Coskunol I. Tuberculosis in diabetics: features in an endemic area. Jpn. J. Infect. Dis. 2009;62:423-7.

14. Khalil IK. The relationship between tuberculosis and diabetes mellitus in patients. Biology Journal of Al-Kufa University. 2011;3(1):195-2.

15. Towhidi M, Azarian A, Asnaashari A. Pulmonary tuberculosis in the elderly.Tanaffos.2008;7(1):52-7.
16. Ezung T, Devi NT, Singh NT, Singh TB. Pulmonary Tuberculosis and Diabetes Mellitus - a study. J Indian Med Assoc. 2002 Jun;100(6):376-9.

17. Soetedjo FA.Perbandingan kepekaan pemeriksaan kuman BTA dari dahak spontan dengan dahak induksi salin 0,9\% pada akhir terapi fase intensif DOTS. 2009.

18. Berger HW, Granada MG. Lower lung field tuberculosis. Chest. 1974;65:5.

19. Perez-Guzman C, Torres-Cruz A, Villarreal-Velarde $\mathrm{H}$, Vargas $\mathrm{MH}$. Progressive age-related changes in pulmonary tuberculosis images and the effect of diabetes. American Journal of Respiratory and Critical Care Medicine. 2000;162. 